\title{
Modal and Harmonic Analysis of Bio-Mimic Corrugated Dragonfly Aerofoil
}

\author{
Md Akhtar Khan, Chinmaya Padhy
}

\begin{abstract}
In this present work, free vibration analysis is carried out on the 2-dimensional bio-mimetic corrugated 'Pantala flavescens' dragonfly forewing. The numerical modeling based on Finite Element Method (FEM) is developed to predict structural limitation of the dragonfly wings Dragonfly wings bend and twist over the course of flight stroke, causing deformation by a combination of elastic and inertial forces. We found that the wing deformation is smaller during the downstroke and it is revealed that the structural maximum beat frequency of a corrugated dragonfly wing is $38.34 \mathrm{~Hz}$ during hovering flight. The modal and harmonic analysis is performed using ANSYS 15 Mechanical APDL to extract the wing's natural frequency and mode shape of corrugated wing which is significant in design, analysis and manufacturing of analogous MAVs structure.
\end{abstract}

Keywords: Free Vibration, structural stability, FEM, corrugated wing, ANSYS 15, modal and harmonic analysis, natural frequencies

\section{INTRODUCTION}

Bio-mimetic aerial vehicle (BMAVs) is a type of micro scaled aircraft that mimics the flapping wing or rigid flexible wing motion of insects. Because of their small size it is difficult to detect and can be deployed easily and relatively inexpensive to fabricate. 'Pantala flavescens' forewing reveals a highly corrugated and complex vein structure that is difficult to mimic exactly as it is. Moreover, the artificial wings of BMAV must be strong enough to withstand the aerodynamic forces produced by flapping motion. In fact, during flight dragonfly wing experiences significant amount of bending and twisting during flight, this will change the aerodynamic as well as the structural response during loading conditions. Dragonfly is unique in nature due to its high maneuverability, low noise and gliding performance makes them most suitable for the BMAVs [1-5].Numerous studies assert that the kind of mechanism and exemplary smart structure of dragonfly wing can withstand array of loads and their combination due to high stability and very thin waxy layer covering consists of chitin and structural proteins [6-12].In this work we have performed the modal and harmonic analysis using ANSYS Classical and

Revised Manuscript Received on April 25, 2020.

* Correspondence Author

Md Akhtar Khan*, Scholar in Department of Mechanical Engineering, GITAM deemed to be University, Hyderabad,India,

Chinmaya Padhy, Department of Mechanical Engineering, GITAM deemed to be University, Hyderabad,India,

(c) The Authors. Published by Blue Eyes Intelligence Engineering and Sciences Publication (BEIESP). This is an open access article under the CC BY-NC-ND license (http://creativecommons.org/licenses/by-nc-nd/4.0/) determined the natural frequency and mode shape of 'Pantala flavescens' dragonfly forewing corrugation. A lot of studies show that the dragonfly being a natural flyer the wings and veins are flexible in nature has rigid flapping wing mechanism and the flapping frequency of dragonfly is nearly between 30 $\mathrm{Hz}$ to $50 \mathrm{~Hz}$ [13]. Few researchers have calculated the natural frequency of dragonfly wing, but Zeng et. Al used non contact quadrant position of sensor to measure natural frequencies of dragonfly wings. Chin et. Al performed a base-excitation modal test and employed spectrum analyzer to calculate resonance frequency of dragonfly wing [14-16]. This work is inspired from the dragonfly wing corrugation located at the radius part of the wing nearly $40 \%$ of the total span of the wing from the root. During gliding flight dragonfly wings are considered as ultra-light aerofoil due to its well defined cross-sectional corrugation and most of the researchers [17-20] have investigated about the aerodynamic benefits but few have done investigation about the free vibration behavior of the dragonfly corrugated aerofoil and mode shape of the corrugated aerofoil.

\section{FREE VIBRATION ANALYSIS}

Static analysis does not take into account variation of load with respect to time. Output in the form of stress, displacement etc. with respect to time could be predicted by dynamic analysis. The determination of natural frequency is helpful for avoiding resonance, reducing noise and as an important meshing check. In free vibration we neglect the effect of damping [21].

$$
[M] \bar{x}+[k] x=0
$$

The above Eq. (i) is ordinary homogeneous linear second order differential equation with constant coefficient. The general solution of the above equation is

$$
x=A \sin \omega t+B \cos \omega t
$$

The above Eq. (ii) is the harmonic equation.

We have done the modal and harmonic analysis using ANSYS 15 Mechanical APDL for 2D dimensional corrugated wing models considering as a beam element and assumed to be clamped at one end [22, 23].

\section{BOUNDARY CONDITION}

As shown in Fig.1, the deformed and un-deformed shape where the wing joint is assumed to be clamped and is constrained in all degrees of freedom (DoF).

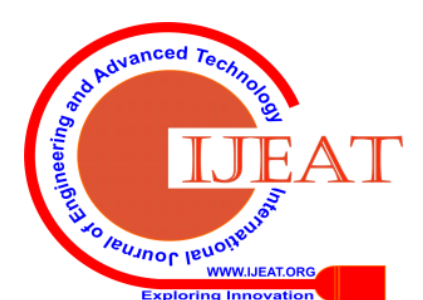


Modal and Harmonic Analysis of Bio-Mimic Corrugated Dragonfly Aerofoil

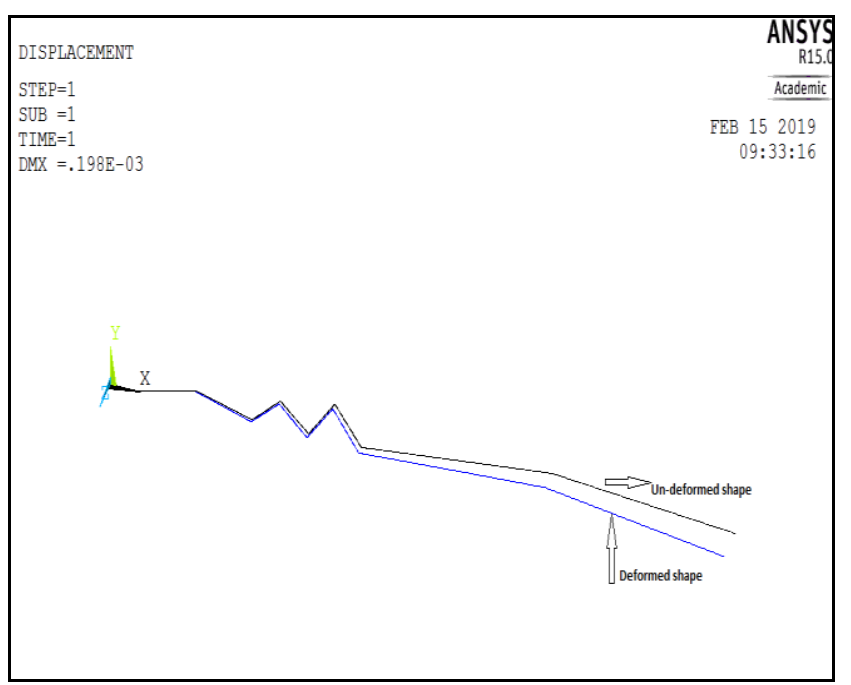

Fig.1. Deformed + Un-deformed Shape

\section{MATERIAL PROPERTIES}

For the classical FEA analysis of the 2-D corrugated structure was considered as isotropic material with a Young's modulus of elasticity as $6100 \mathrm{~N} / \mathrm{mm}^{2}$. The Poisson's ratio is assumed to be 0.49 .The material density of wing is taken as 1200 $\mathrm{kg} / \mathrm{m}^{3}$. The pressure applied on the beam is $-4.5 \times 10^{-6}$ $\mathrm{N} / \mathrm{mm}^{2}[23,24]$.

\section{MODAL ANALYSIS RESULTS}

For modal analysis the 2-D corrugated wing is considered as beam of $110 \mathrm{~mm}$ and thickness is $4 \mathrm{~mm}$ [22] .The beam is clamped at one of its end and the element is taken as 2 node 188 or Beam 188.The ten mode shapes are plotted Using software ANSYS 15 Mechanical APDL and the natural frequency of the system is calculated. Before modal analysis the deformed and undeformed shape is plotted as shown in Fig. 1 and have maximum nodal displacement of $0.198 \times 10^{-3}$ as shown in Fig.2.

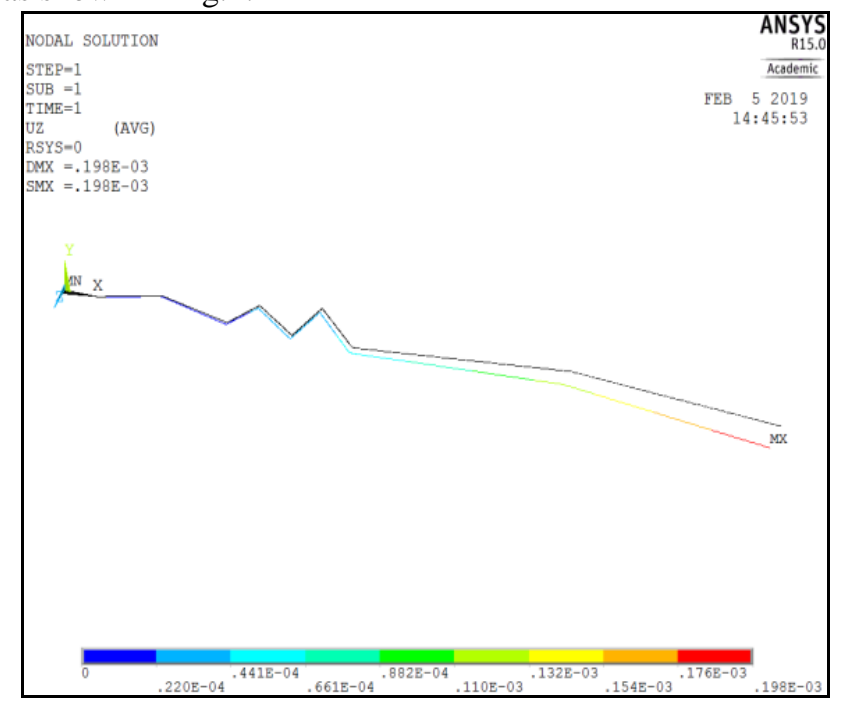

Fig.2. Z-component displacement

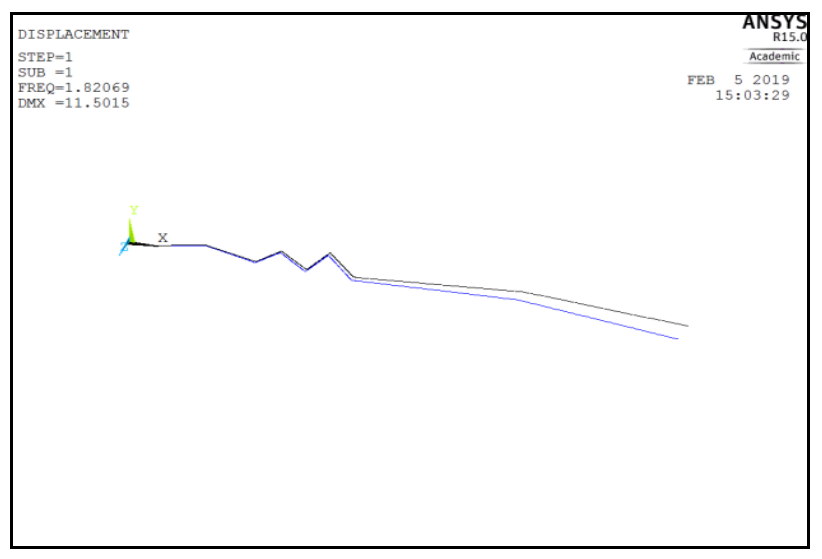

Fig. 3(a). Mode shape 1 (f=1.8207 Hz)

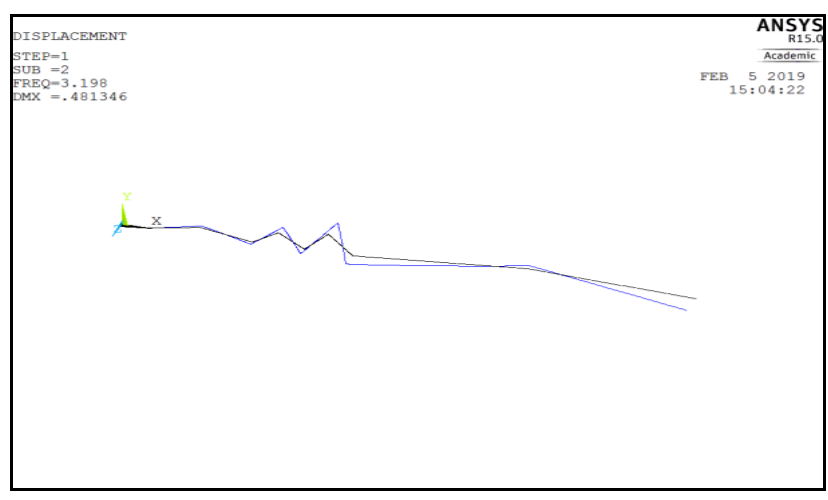

Fig.3 (b). Mode shape 2 (f=3.198 Hz)

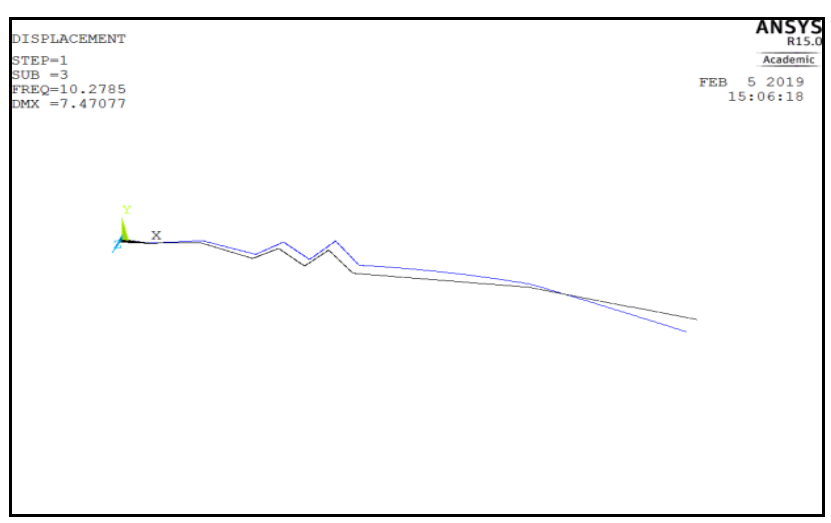

Fig.3 (c). Mode shape $3(\mathrm{f}=\mathbf{1 0 . 2 8 H z})$

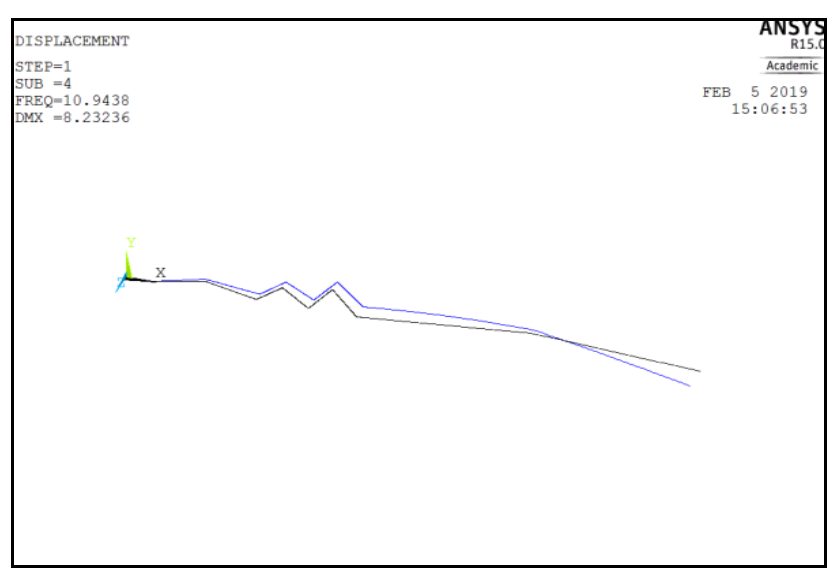

Fig. 3(d). Mode shape $4(f=10.94 H z)$

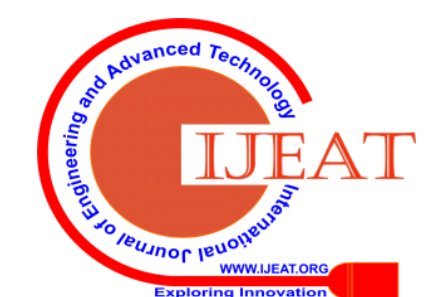




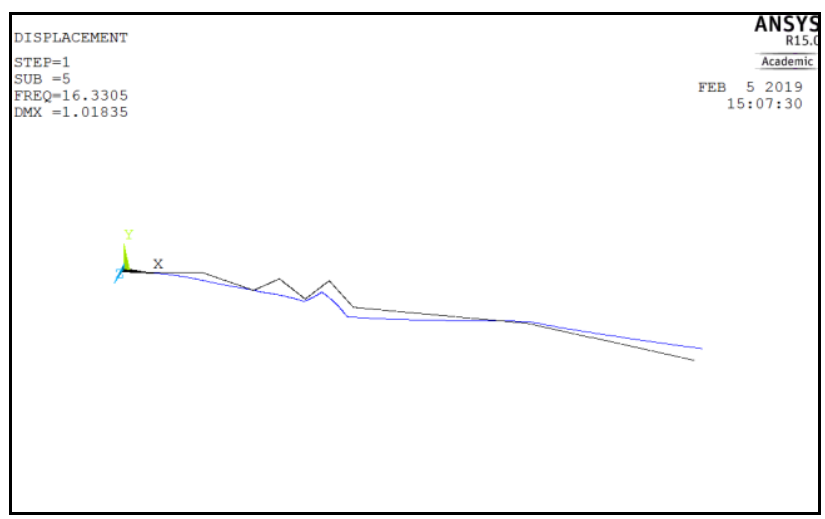

Fig. 3(e). Mode shape $5(f=16.33 H z)$

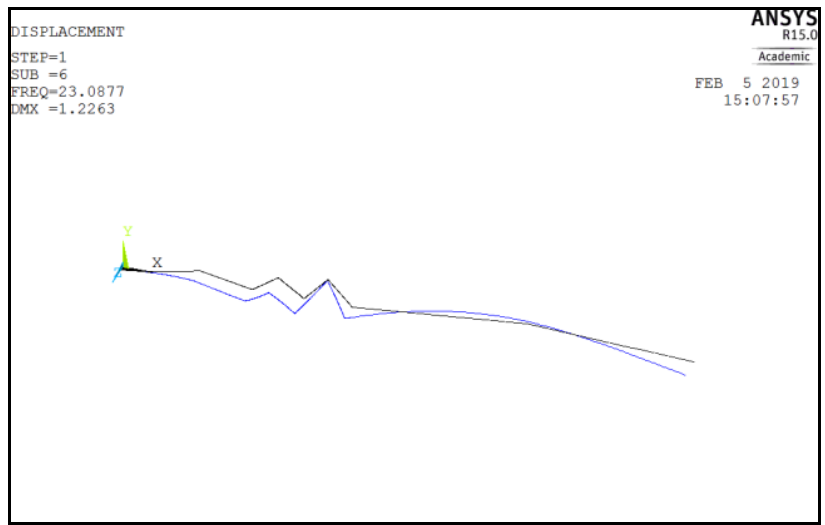

Fig. 3(f). Mode shape $6(f=23.08 H z)$

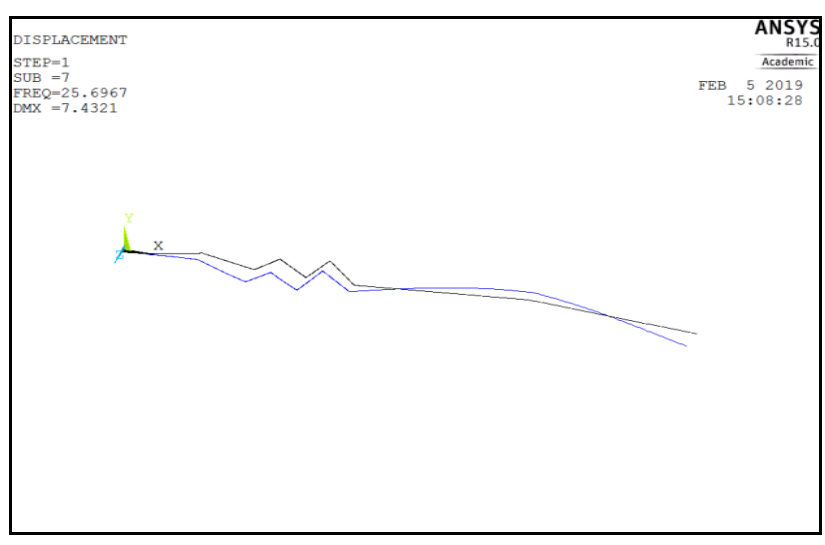

Fig. 3(g). Mode shape 7 (f=25.697 Hz)

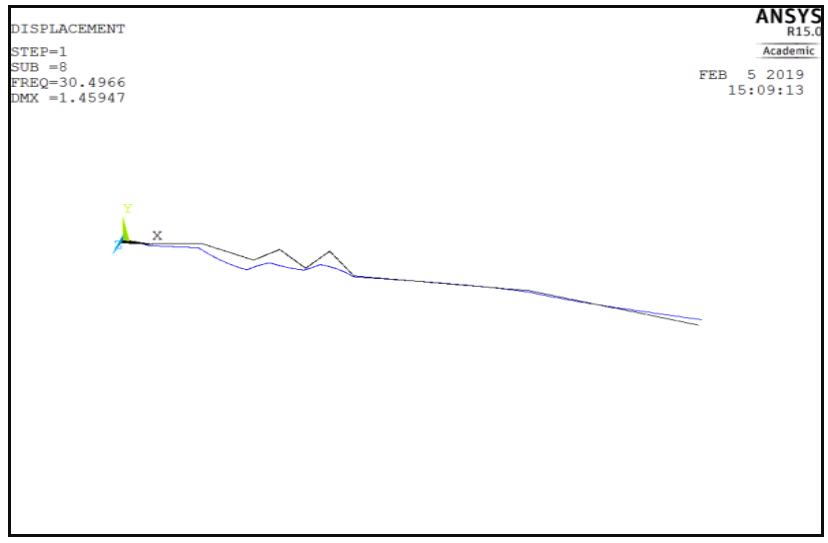

Fig. 3(h). Mode shape $8(f=30.497 \mathrm{~Hz})$

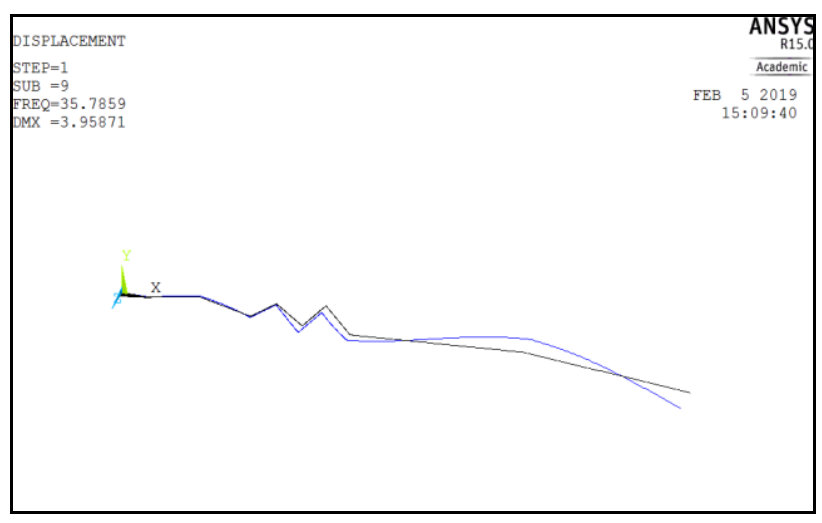

Fig. 3(i). Mode shape $9(f=35.786 ~ H z)$

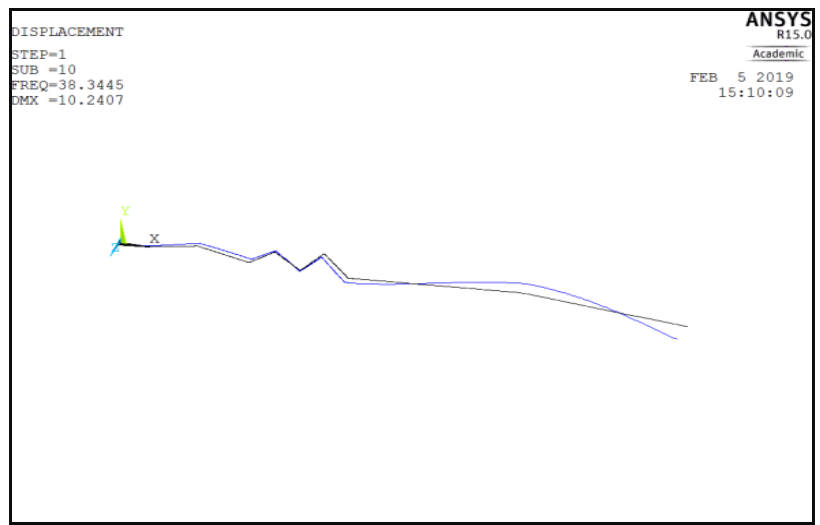

Fig. 3(j). Mode shape $10(f=38.34 \mathrm{~Hz})$

Once the deformed + undeformed shape is plotted the static structural analysis is changed to modal analysis of the 2-D corrugated aerofoil and 10 mode shapes of the wavy corrugated dragonfly pleated structure is plotted to find the natural frequency of the system. From the above modal plots we can observe that the mode shapes consists of bending and twisting deformation. It is observed that at first mode shape as shown in Fig. 3(a) the corrugated wing structure experiences more bending than twisting and the maximum nodal displacement is observed as $11.50 \mathrm{~mm}$ and the natural frequency of the system can be calculated as shown in Eq. (3).

$$
\omega_{n}=\sqrt{\frac{k}{m}}
$$

The ratio between the dynamic amplitude $X$ and static $X_{s}$, is called as magnification factor

$$
\frac{X}{x_{x}}=\frac{1}{1-\left(\frac{\omega}{\omega_{n 2}}\right)^{2}}
$$

where, $\omega_{\mathrm{n}}$ is the natural frequency of the system.

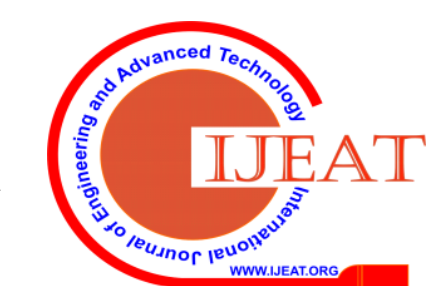


Modal and Harmonic Analysis of Bio-Mimic Corrugated Dragonfly Aerofoil

Table- I Deformation and Natural frequency of the corrugated wing structure

\begin{tabular}{|c|c|c|c|}
\hline $\begin{array}{l}\text { Number of Mode } \\
\text { Shape }\end{array}$ & $\begin{array}{c}\text { Frequency(Hz) } \\
(\omega)\end{array}$ & $\begin{array}{c}\text { Natural Frequency(rad/sec) } \\
\left(\omega_{\mathrm{n}}\right)\end{array}$ & Kind of Deformation \\
\hline 1 & 1.8207 & 11.44 & Bending \\
\hline 2 & 3.198 & 20.09 & Twisting \\
\hline 3 & 10.279 & 64.58 & Bending+Twisting \\
\hline 4 & 10.944 & 68.73 & Twisting \\
\hline 5 & 16.331 & 102.62 & Twisting \\
\hline 6 & 23.088 & 145.13 & Bending \\
\hline 7 & 25.697 & 161.45 & Bending+Twisting \\
\hline 8 & 30.497 & 191.62 & Bending \\
\hline 9 & 35.786 & 224.85 & Bending+Twisting \\
\hline
\end{tabular}

Since, By Putting the values of flapping frequency $(\omega)$ and natural frequency $\left(\omega_{n}\right)$ in Eq. 4 , we obtained the magnification factor value as 1.02.It demonstrates that the inertia force on the wing is very less in comparison to the elastic force during flapping motion .The graphical variation of displacement vs. natural frequency and frequency with respect to set of values is plotted below as shown in Fig.4 and Fig.5.

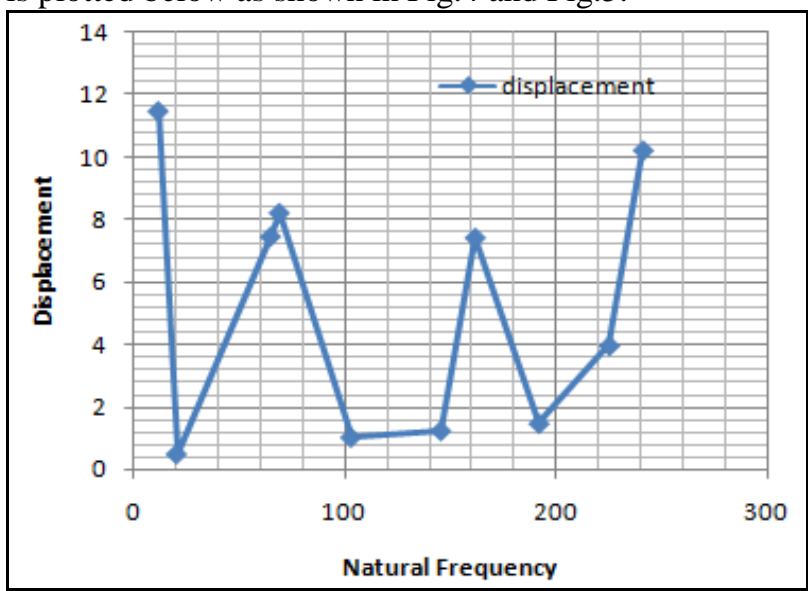

Fig. 4. Displacement vs. natural frequency

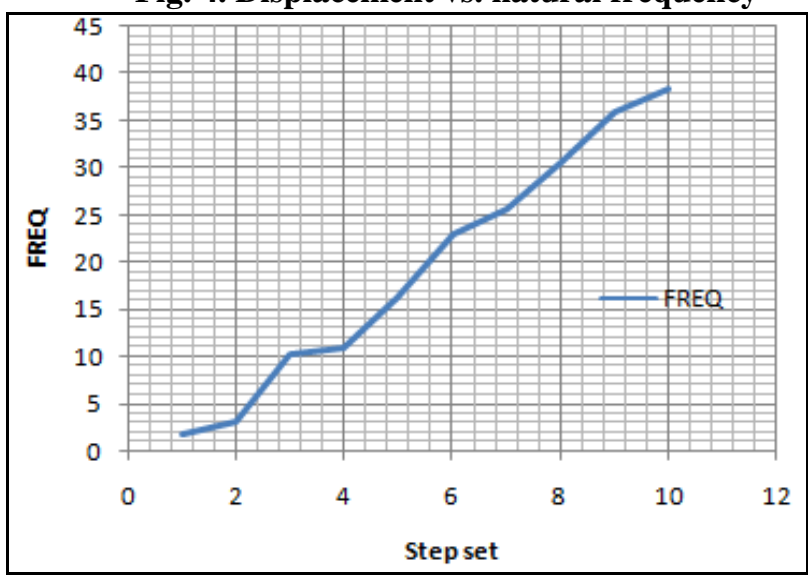

Fig. 5. Frequency vs. time step

\section{HARMONIC ANALYSIS}

As the 2-D corrugated system is under harmonic motion , it is always better to estimate the time history plot of the structure
nature.Harmonic response analysis helps to determine the steady state response of a linear structure to loads that vary sinusoidally (harmonically) with time. The transient vibrations, which occur at the beginning of the excitation, are not accounted for in a harmonic response analysis

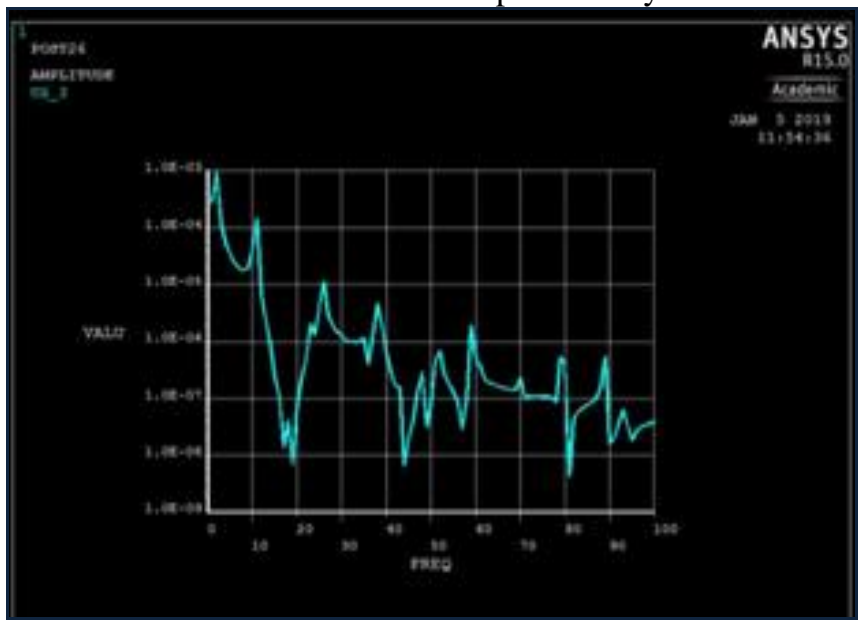

Fig. 6. Amplitude vs. Frequency

Since, from Fig. 6 we can interpret that the amplitude varies irregularly with respect to the frequency modulation of the 2-d corrugated system. By this we understood that the corrugated structure can withstand varying loads at regular interval of time.

\section{CONCLUSION}

The present work studied free vibration analysis which includes the modal and harmonic analysis of the 2-d corrugated aerofoil. The modal analysis shows that the wing can resist longitudinal bending as well as the twisting. The fundamental frequency of dragonfly 2-d corrugated structure is estimated about $1.821 \mathrm{~Hz}$ or $11.44 \mathrm{rad} / \mathrm{s}$ and the maximum frequency for the $10^{\text {th }}$ mode shape is $38.34 \mathrm{~Hz}$ or $240.89 \mathrm{rad} / \mathrm{s}$. Some mode shape consists of bending and some twisting and also the combination of bending and twisting. We also observed that the dynamic deformation amplitude is 1.02 times of the static amplitude by using magnification factor. So, the corrugated wing structure can withstand both aerodynamic and elastic load. In contrast, the wing deformation and angle of attack of dragonfly like wings are under more control through high fidelity aero-elastic tailoring .

Published By:

Blue Eyes Intelligence Engineering

\& Sciences Publication

(C) Copyright: All rights reserved.

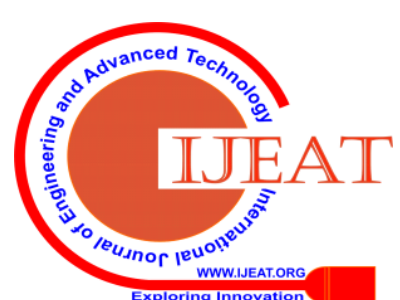


The natural frequency obtained from this study and determination of magnification factor helps in the bio-mimetic design of micro air vehicles.

\section{ACKNOWLEDGMENT}

We gratefully acknowledge the support from the GITAM University for providing the Computational Simulation facility for doing this research work more effectively.

\section{REFERENCES}

1. D. J. S. Newman, R. J. Wootton, An approach to the mechanics of pleating in dragonfly wings, Journal of Experimental Biology, 125: 361-372,1986.

2. C. J. C. Rees, Aerodynamic properties of an insect wing section and a smooth aerofoil compared, Nature, 258: 141-142, 1975a,DOI: 10.1038/258141a0.

3. Combes SA. ,Materials, structure, and dynamics of insect wings as bioinspiration for MAVs,Encyclopedia of Aerospace Engineering:Vol.7,Part 34,3 ${ }^{\text {rd }}$ ed. New York,John Wiley and Sons,2010

4. S. Sudo, K. Tsuyuki, J. Tani, Wing morphology of some insects, JSME International Journal Series C- Mechanical Systems, Machine Element sand manufacturing, 43: 895-900, DOI: 10.1299/jsmec.43.895, 2000.

5. Mc Lendon,R.W and Whitcomb,J.D.2003,Investigation into Dragonfly Win g structure and composite Fabrication.

6. A.B.Kessel ,U.Philippi ,W. Nachtgall,Biomechanical Aspects of the insect wing:an analysis using the finite element method,Comp.Biol.Med.28 (1998) 423-437.

7. R. J. Wootton, Function, homology and terminology in insect wings, $\begin{array}{llll}\text { Systematic } \quad \text { Entomology, 81- } & \text { 93, }\end{array}$ DOI:10.1111/j.1365-3113.1979.tb00614.x,1979.

8. R. J. Wootton, Support and deformability in insect wings, Journal of Zoology, 193:447-468, 10.1111/j.1469-7998.1981.tb01497.x,1981.

9. Ellington CP (1999), The novel aerodynamics of insect flight: application s to micro-air vehicles.J.exp. Biol 202:3439-3448

10. J. P. Whitney, Design and performance of Insect scale flapping wing vehicles, Harvard university, 2012.

11. M. Okamoto, K. Yasuda, and A. Azuma, Aerodynamic Characteristics of the wings and the Body of a dragonfly, Journal of experimental biology, Vol.199, pp.281-294, 1996.

12. C. J. C. Rees, Aerodynamic properties of an insect wing section and a smooth aerofoilcompared,Nature, 258, 141-142, 1975a.

13. H. Liu, C. P. Ellington, K. Kawachi, C. Van Den Berg, and A. P. Willmott, A computational fluid dynamic study of hawkmoth hovering, J. Exp. Biol.,201, 461-477, 1998.

14. J.S. Chen, J.Y. Chen, Y.F. Chou, On the natural frequencies and mode shapes of dragonfly wings, J.Sound and Vibration 313 (2008) 643-654.

15. L.Zeng, H.Matsumoto, S.Sunada,T .Ohnuki, K.Kawachi, Two -Dimensional non contact measurement of the natural frequencies of dragonfly wings using a quadrant position sensor,J.Optical Engineering 34 1995(1226-1231).

16. M.Darvizeh, A.Darvizeh, H.Rajabi, A.Rezai, Free Vibration analysis of dragonfly wings using finite element method,Int. Journal of Multiphysics,vol.3,2019.

17. S.R.Jongerius, D.Lentink, Structural Analysis of dragonfly wing,ExperimentalMechanics,doi-10.1007/s11340-010-9411-x,2010.

18. Khan MA, Padhy C, Nandish M ,Rita K,Computational Analysis of Bio-Inspired Corrugated Airfoil with Varying Corrugation Angle, Journal of Aeronautics \& Aerospace Engineering, vol. 7, doi-10.4172/2168-9792, 2018.

19. Khan A, Padhy C. Aerodynamic and structural analysis of Bio-mimetic corrugated wing. Fluid Mechanics Research Int J.2019;3(2):61-67 , DOI: 10.15406/fmrij.2019.03.00053

20. S.S.Rao, Mechanical Vibration, Addison-Wesley, New York,(1995)

21. R. J. Wootton, R. C. Herbert, P. G. Young, K. E. Evans, Approaches to the structural modeling of insect wings,Phil Trans $\mathrm{R}$ Soc B,358:1577-1587, 2003.

22. Wainwright SA,Biggs WD ,Currey JD and Gosline JM(1982),Mechanical design in organism, Princeton University Press.

23. Vincent JFV,Wegst UGK (2004),Design and mechanical properties of insect cuticle ,Arthropod Stru. Dev 33:187-199.

24. F.Song,K.W.Xiao, K. Bayi, Y.L.Bai, Microstructure and Nano-mechanical properties of the wing membrane of dragonfly, Mat.Sci.Eng.A, 457 (2007) 254-260.
Md Akhtar khan , Ph.D Part time Research Scholar and Asst. Professor in the department of Aerospace Engineering,GITAM deemed to be University Hyderabad. I have published 18 International peer reviewed journal research papers. I have been bestowed with prestigious National Awards like Research Excellence Award, Best International Conference paper Awards. My research interest is fluid dynamics, Low Reynolds number flyer, steady and unsteady Aerodynamics.I am life time member of Aeronautical society of India.

Dr.Chinmaya Padhy, Associate Professor in the department of Mechanical Engineering,GITAM deemed to be University ,Hyderabad .He has Published 10 papers in peer reviewed journals .His research interest is hydrodynamics ,Fluid dynamics, Manufacturing and Metallurgy. He is member of Indian science congress Association. 